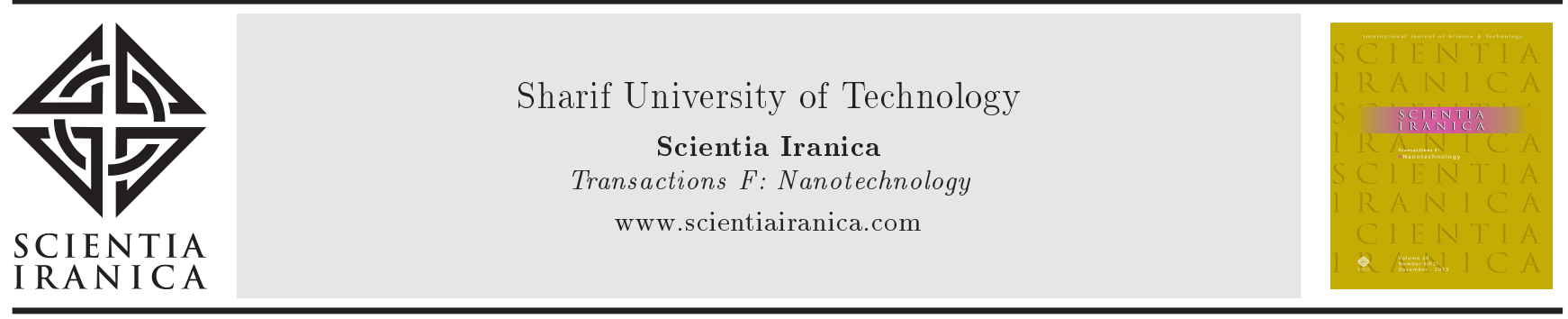

\title{
Mechanical reinforcement of urinary bladder matrix by electrospun polycaprolactone nanofibers
}

\author{
A.M. Ghafari ${ }^{\mathrm{a}, \mathrm{b}}$, S. Rajabi-Zeleti ${ }^{\mathrm{a}}$, M. Najic, M.H. Ghanian ${ }^{\mathrm{a}}$ and H. Baharvand $^{\mathrm{a}, \mathrm{d}, *}$ \\ a. Department of Cell Engineering, Cell Science Research Center, Royan Institute for Stem Cell Biology and Technology, ACECR, \\ Tehran, Iran. \\ b. Department of Chemical \& Petroleum Engineering, Sharif University of Technology, Tehran, Iran. \\ c. Urology and Nephrology Research Center, Shahid Beheshti University of Medical Sciences, Tehran, Iran. \\ d. Department of Developmental Biology, University of Science and Culture, ACECR, Tehran, Iran.
}

Received 8 August 2016; accepted 29 October 2016

\section{KEYWORDS \\ Nanofiber; \\ Bladder matrix; \\ Polycaprolactone; \\ Hybrid scaffold; \\ Bladder tissue \\ engineering.}

\begin{abstract}
For a successful repair and reconstruction of bladder tissue, fabrication of scaffolds with proper biochemical and biomechanical characteristics is necessary. Decellularized bladder tissue has been proposed in previous studies as a gold standard material for scaffold fabrication. However, weak mechanical properties of such a loadbearing tissue has remained a challenge. Incorporation of both biological and synthetic materials has been known as an effective strategy for improving mechanical and biological properties of the scaffolds. In the present work, a simple process was developed to fabricate hybrid hydrogel scaffolds with a biomimetic architecture from the natural urinary bladder extracellular matrix (ECM) and synthetic polycaprolactone (PCL) nanofibers in order to obtain a scaffold with optimized mechanical and biological properties for bladder tissue engineering. To this end, the ECM gel was derived from rat bladder, and the electrospun PCL nanofibers were embedded within the gel, followed by incubating the composite to shape the hybrid hydrogel. These reinforced scaffolds showed more structural integrity and mechanical stability. The introduced concept of nanofiber-reinforced ECM can be applied as a promising platform in engineering of bladder or other load-bearing soft tissues.

(C) 2017 Sharif University of Technology. All rights reserved.
\end{abstract}

\section{Introduction}

In 1993, Langer and Vacanti highlighted tissue engineering from previous studies to describe a new interdisciplinary field that employs engineering rules toward the evolution of biological substitutes [1]. Nearly 25 years later, many advances have been made with regard to a wide range of tissues and organs, recently reviewed by Langer and Vacanti [2]. Tissue engineering relies on the body's natural ability to regenerate. The two

*. Corresponding author.

E-mail address: baharvand@royaninstitute.org ( $H$. Baharvand)

doi: $10.24200 /$ sci. 2017.4418 tissue engineering strategies, i.e. scaffold alone or cell seeded matrices, have been studied in the bladder tissue engineering [3].

Structure and function of the bladder are simpler than those of complex organs are such as kidney and heart. The primary function of bladder as a part of the urinary system in body is to store and remove urine [4]. When this reservoir operates properly, high capacity is maintained and low pressure is kept; it also protects the upper urinary track from any pressure and other damages [3]. Some conditions can widely lead to bladder dysfunction including cancer, infection, trauma, neurological control disorders, and congenital disorders [4]. These conditions require suitable reconstructive procedures that can be performed with heterologous or non-heterologous tissues or artificial 
materials. Gastrointestinal segments are used mostly in these bladder reconstruction procedures [5]; however, incorporation of these tissues into urinary systems can cause several complications such as urolithiasis, metabolic disturbances, increased mucous production, and malignant disease [6]. These problems have led to advanced research into bladder tissue engineering [7].

By means of tissue engineering approach, many innovative methods have been developed for bladder reconstruction differing in biomaterials, cells, and growth factors [8]. Generally, three main strategies have been used in bladder tissue engineering for the fabrication of artificial bladder tissue or entire bladders, including engineering entire, partial or patch structures for further applications [4]. In 2001, Atala successfully implanted a canine bladder as the first tissue engineered organ in human [9] that is a proven document for probable results of tissue engineering approaches in the regeneration of bladder tissue or in the construction of artificial bladder [8]. Here, we have employed the second strategy to fabricate a cell-free gel-patch scaffold, which is more prone to commercialization and translation to clinic.

Biomaterials in the bladder tissue engineering are biological materials, such as acellular tissue matrices $[10,11]$, derived from natural sources or synthetic polymers, such as polycaprolacton (PCL) [7,12], using various fabrication techniques such as electrospinning, solvent casting, particulate leaching, 3D printing, gas foaming, phase separation, and freeze drying $[9,13-$ 16]. Incorporation of both biological and synthetic materials along with the goal of reinforcing matrices' mechanical properties and optimizing biological properties has been proposed in previous studies [12].

In this study, a simple process is developed to fabricate hybrid hydrogel scaffolds with a well-defined architecture from the urinary bladder matrix and PCL nanofibers. These reinforced scaffolds showed better mechanical properties, proposing a promising approach to regenerative medicine and tissue engineering applications.

\section{Materials and method}

\subsection{Decellularization of rat bladder tissue}

Rat bladder tissues were decellularized, as previously described [11]. In brief, rat bladder tissue slices were washed with Dulbecco's Phosphate-Buffered Saline (PBS) and Sodium Dodecyl Sulfate (SDS, 1\% w/v) for $24 \mathrm{~h}$. The tissue was finally treated with a nuclease solution, and then washed in sterile PBS. Histological and DNA analyses were performed for test and control groups.

\subsection{Preparation of bladder-derived gel}

Milled acellular bladder powder was allowed to digest in pepsin at $17 \mathrm{mg} / \mathrm{ml}$ that was dissolved in $0.5 \mathrm{M}$ acetic acid for about $72 \mathrm{~h}$ under constant stirring. Then, the solution was brought to $\mathrm{pH} 7.4$ by the addition of $1 \mathrm{M}$ $\mathrm{NaOH}$ and 10X PBS, forming a viscous gel solution.

\subsection{Electrospinning PCL nanofibers}

The polymer solution with concentration of 12 wt.\% in Chloroform and Methanol (3:1) was prepared by continuous stirring to dissolve pelletized PCL. The solution was placed in a 10 cc syringe with a 20 -gauge blunt tip needle and electrospun using a high-voltage DC power supply set to $17 \mathrm{kV}$, a $15 \mathrm{~cm}$ tip-to-substrate distance, and a $1.5 \mathrm{ml} / \mathrm{h}$ flow rate. The optimized processing parameters are summarized in Table 1.

\subsection{Fabrication of hybrid composite}

A simple process was developed to generate hybrid hydrogel scaffolds with a well-defined architecture from urinary bladder matrix and PCL nanofiber mat (Figure 1).

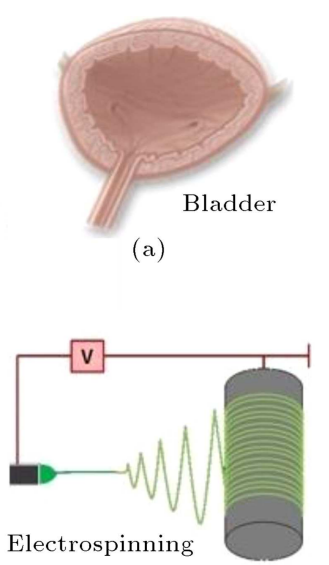

(d)
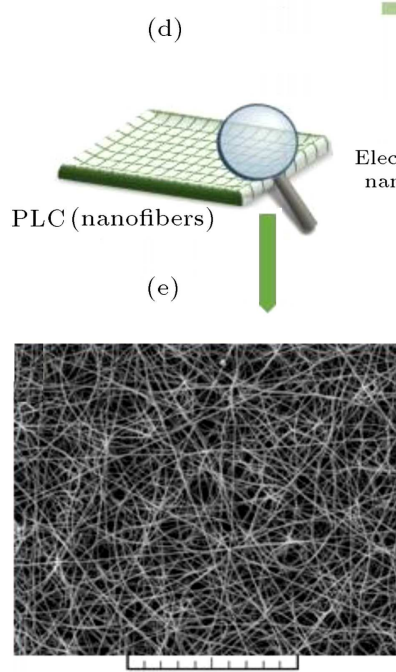

(g)

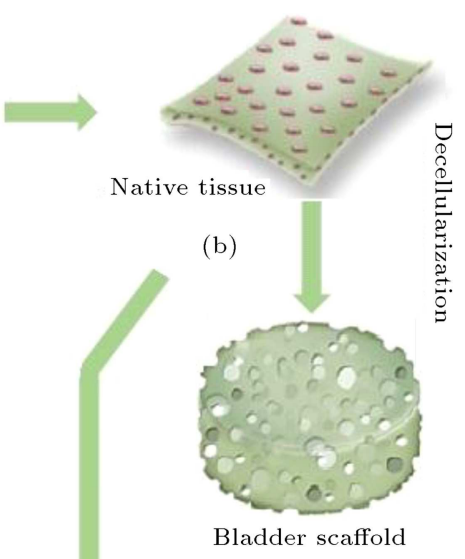

(c)

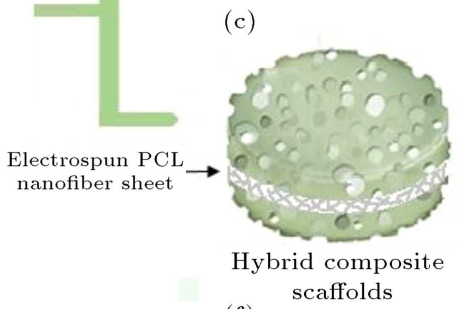

(f)

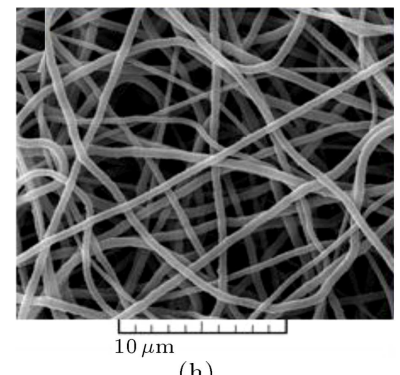

(h)
Figure 1. Fabrication of hybrid composite: (a) Bladder organ, (b) native tissue slice, (c) decellularized bladder scaffold, (d) electrospining device, (e) PCL nanofiber mats, (f) hybrid composite, and $(\mathrm{g}, \mathrm{h})$ SEM images of electrospun PCL nanofibers. 
Table 1. Processing parameters for electrospinning PCL.

\begin{tabular}{cccc}
\hline $\begin{array}{c}\text { Voltage } \\
(\mathbf{k V})\end{array}$ & $\begin{array}{c}\text { Distance } \\
(\mathbf{c m})\end{array}$ & $\begin{array}{c}\text { Flow rate } \\
(\mathbf{m l} / \mathbf{h})\end{array}$ & $\begin{array}{c}\text { Rotation speed } \\
(\mathbf{r p m})\end{array}$ \\
\hline 17 & 15 & 1.5 & 250
\end{tabular}

At first, a layer of gel solution $(0.6 \mathrm{ml})$ was incubated in a small cylinder $(1 \mathrm{~cm}$ diameter $)$ that shaped the gel for $10 \mathrm{~min}$, and then we put a nanofiber mat on the semi-cured gel; next, the second layer of the gel $(0.4 \mathrm{ml})$ was injected into the cylinder for 15 min of incubation. Definite amount of solution $(1 \mathrm{ml})$ was injected into the cylinder and incubated with or without PCL mat for test and control group, respectively.

\section{Results and discussion}

Here, we demonstrated the complete removal (>99\%) of cellular contents through SDS decellularization protocol. By using this mild technique, native tissue components, which play pivotal roles in original ECM construct, have been thoroughly preserves [17]. Histologic analysis of native bladder showed no evidence of intact nuclear material on H\&E staining as compared to native bladder (Figure 2(a)). As shown by MT stain-

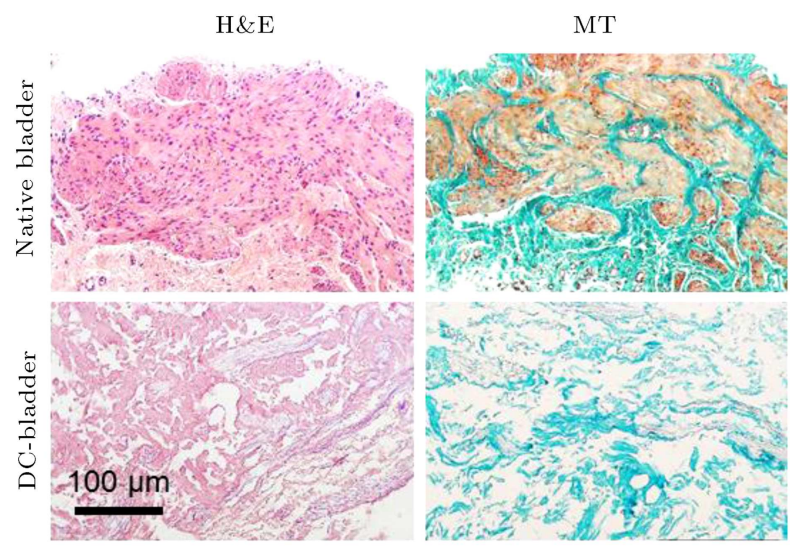

(a)

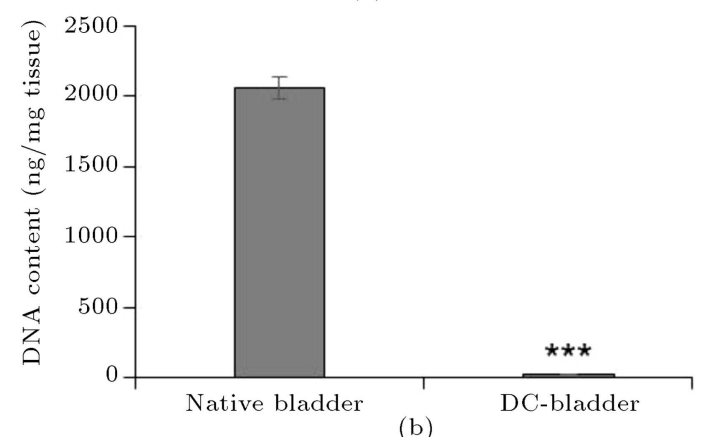

Figure 2. Characterization of decellularized rat bladder tissue: (a) Histological analysis and (b) DNA content confirm the absence of nuclei and demonstrates the preservation of a DC-bladder structure compared with native bladder (*** presents $P$-value $<0.001, n=3$ ).

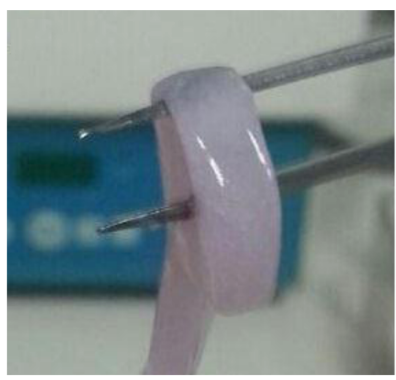

(a)

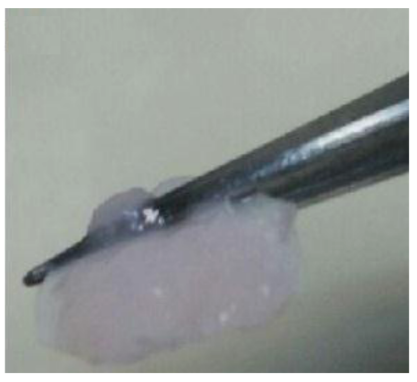

(b)
Figure 3. (a) As-prepared decellularized bladder hydrogel, and (b) hydrogel/nanofiberous hybrid scaffold. The hybrid scaffold shows more structural integrity.

ing, the overall matrix histoarchitecture and major structural components, i.e. collagen, remained intact. To determine the presence of decellularized tissue (DCbaldder), DNA measurement was performed.

After decellularization, there was a $36 \pm 12 \mathrm{ng}$ $\mathrm{DNA} / \mathrm{mg}$ wet weight compared to the $7600 \pm 600 \mathrm{ng}$ DNA/mg wet weight found in native bladder tissue (Figure 2(b)).

Although the mechanical properties of the reinforced hybrid hydrogels were weaker than those urinary bladder tissues, the enhancement brought by electrospun PCL fibers was considerable (Figure 3). Not only the mechanical properties of hydrogel improved, but also handling of this scaffold was promoted during suturing. We found that further mechanical testing is not essential in our study and reinforcement can be observed with naked eye (Figure 3). Hybrid hydrogel/PCL scaffold exhibited a range of biological and mechanically tunable profiles. Thus, these scaffolds have the potential to meet an assortment of cellular and mechanical demands required for engineering tissues.

\section{Conclusion}

We successfully fabricated a 3D hybrid hydrogel/PCL with biomimetic properties for urinary tissue engineering. It can be a good candidate and a promising approach in regenerative medicine.

\section{Acknowledgment}

This study was supported by a grant from Royan Institute. The authors would like to express their appreciation to all members of cell engineering group at Royan Institute.

\section{References}

1. Langer, R. and Vacanti, J. "Tissue engineering", Science, 260, pp. 920-926 (1993).

2. Levenberg, S. and Langer, R. "Advances in tissue en- 
gineering", Current Topics in Developmental Biology, 61, pp. 113-134 (2004).

3. Stanasel, I., Mirzazadeh, M. and Smith, J.J. "Bladder tissue engineering", Urologic Clinics of North America, 37(4), pp. 593-599 (2010).

4. Birla, R. Introduction to Tissue Engineering: Applications and Challenges, John Wiley \& Sons (2014).

5. Atala, A. "Tissue engineering of human bladder", British Medical Bulletin, 97(1), pp. 81-104 (2011).

6. Atala, A., Bauer, S.B., Soker, S., Yoo, J.J. and Retik, A.B. "Tissue-engineered autologous bladders for patients needing cystoplasty", The Lancet, 367(9518), pp. 1241-1246 (2006).

7. Van Ba, O.L., Aharony, S., Loutochin, O. and Corcos, J. "Bladder tissue engineering: A literature review", Advanced Drug Delivery Reviews, 82, pp. 31-37 (2015).

8. Sloff, M., Simaioforidis, V., de Vries, R., Oosterwijk, E. and Feitz, W. "Tissue engineering of the bladderreality or myth? A systematic review", The Journal of Urology, 192(4), pp. 1035-1042 (2014).

9. Larson, C. and Shepherd, R. "3D bioprinting technologies for cellular engineering", Microscale Technologies for Cell Engineering, Springer International Publishing, pp. 69-89 (2016).

10. Song, L., Murphy, S.V., Yang, B., Xu, Y., Zhang, Y. and Atala, A. "Bladder acellular matrix and its application in bladder augmentation", Tissue Engineering Part B: Reviews, 20(2), pp. 163-172 (2013).

11. Rajabi-Zeleti, S., Jalili-Firoozinezhad, S., Azarnia, M., Khayyatan, F., Vahdat, S., Nikeghbalian, S., Khademhosseini, A., Baharvand, H. and Aghdami, N. "The behavior of cardiac progenitor cells on macroporous pericardium-derived scaffolds", Biomaterials, 35(3), pp. 970-982 (2014).

12. Gill, B.C., Damaser, M.S. and Chermansky, C.J. "Future perspectives in bladder tissue engineering", Current Bladder Dysfunction Reports, 10(4), pp. 443448 (2015).

13. Murphy, S.V. and Atala, A. "3D bioprinting of tissues and organs", Nature Biotechnology, 32(8), pp. 773-785 (2014).

14. Bajaj, P., Schweller, R.M., Khademhosseini, A., West, J.L. and Bashir, R. "3D biofabrication strategies for tissue engineering and regenerative medicine", Annual Review of Biomedical Engineering, 16, p. 247 (2014).

15. Park, H.J., Lee, O.J., Lee, M.C., Moon, B.M., Ju, H.W., Min Lee, J., Kim, J.H., Kim, D.W. and Park, C.H. "Fabrication of 3D porous silk scaffolds by particulate (salt/sucrose) leaching for bone tissue reconstruction", International Journal of Biological Macromolecules, 78, pp. 215-223 (2015).

16. Jiang, J., Carlson, M.A., Tesink, M.J., Wang, H., MacEwan, M.R. and Xie, J. "Expanding twodimensional electrospun nanofiber membranes in the third dimension by a modified gas-foaming technique", ACS Biomaterials Science \& Engineering, 1(10), pp. 991-1001 (2015).
17. Place, E.S., Evans, N.D. and Stevens, M.M. "Complexity in biomaterials for tissue engineering", Nature Materials, 8(6), pp. 457-470 (2009).

\section{Biographies}

Amir Mohammad Ghafari received his BS degree in Chemical Engineering from Sharif University of Technology. Currently, he is a first-year Master student of Biotechnology at the Department of Chemical Engineering at Noshirvani University of Technology and also working at the Royan Institute in the cell engineering group with Dr. Baharvand.

Sareh Rajabi-Zeleti received her BSc degree in General Biology from the University of Payam Noor, Sari, Iran, and also received $\mathrm{MSc}$ and $\mathrm{PhD}$ degrees from Kharazmi University, Tehran, Iran in 2008 and 2013, respectively. Since 2009, she has been with Royan Institute. Dr. Rajabi-Zeleti is currently doing her postdoctoral research fellowship on bioengineering area. Her research interests include the design and fabrication of a variety of biomaterials and analysis of interaction of stem cells with different scaffolds for cardiovascular, skin and muscle tissue engineering.

Mohammad Naji is a Research Assistant at Urology and Nephrology Research Center. He received BSc degree in Animal Biology from Guilan University, Rasht, Iran. After receiving MSc degree in Developmental Biology, he received his $\mathrm{PhD}$ degree in Reproductive Biology from Tehran University of Medical Sciences, Tehran, Iran. Currently, he mainly concentrates on reconstructive urology through tissue engineering. Bladder tissue engineering by new designs, novel materials, and innovative assessment models comprises mainstream of his research.

Mohammad Hossein Ghanian received his BSc degree in Chemical Engineering at Isfahan University of Technology in 2010. He focused on Polymer Engineering for biomedical applications and received his master degree from Iran Polymer and Petrochemical Institute in 2012. At the time, he started his PhD in Polymer Engineering at Amirkabir University of Technology. He is also a Research Assistant in Royan Bioengeering Group science, 2010, working on developing micro/nanostructures for drug delivery and tissue engineering applications.

Hossein Baharvand is a distinguished Professor and the Director of Royan Institute for Stem Cell Biology and Technology, where he firstly joined in 1995. He received his BSc degree in Biology from Shiraz University in 1994 and MSc degree in Developmental Biology from Shahid Beheshti University, Tehran, in 
1996. He received his $\mathrm{PhD}$ in Cell and Developmental Biology from Khwarizmi University (formerly Tarbiat Moallem University) in 2004. He is the founder of the Department of Stem Cells established in 2002 as well as Royan Institute for Stem Cell Biology and Technology in 2010. He is also appointed as the Head of the Department of Developmental Biology at University of Science and Culture (2006-now). For the first time, he generated the mouse and human embryonic stem cells (2003) and induced pluripotent stem cells (2008) in Iran. This has enabled his team to pursue many avenues of research into translational research and regenerative medicine. His focus of research interests lies in improving the translational research and regenerative medicine, mainly through the understanding of Stem Cells and Developmental Biology and Biologically inspired Engineering. He has been working on transdifferentiation and pluripotent stem cell differentiation into cardiomyocytes, neural cells, hepatocytes, and beta cells. He has also been studying the pluripotency mechanism and germ cell biology. In addition, he has been investigating the biologically inspiring engineering on stem cells and developmental biology. He has also been contributing to clinical trials and tissue-specific stem cell transplantation, as well as developing cell manufacturing. He has given numerous invited talks and tutorials. He is the editor of four international books, which were published by
Springer (2010 and 2012) and John Wiley, USA (2015), and has published 267 international and 102 national peer-reviewed papers, as well as seven chapters in international books, seven books in Persian, and eight translated English text books into Persian. As of Sep 2016, Google Scholar reports over 5600 citations and hindex 40 to his work. He is currently an editorial board member of eight international journals (e.g., Journal of Biological Chemistry and Scientific Reports from Nature Publishing Group). He has received 29 international and national awards, including 10th (2004), 12th (2006), and 17th (2012) annual Razi research awards, on medical science hosted by Iran Ministry of Health and Medical Education and 26th Khwarizmi International Award (2013), hosted by Iran Ministry of Science. He is the winner of the Islamic Educational, Scientific, and Cultural Organization (ISESCO) Prize for research in the field of Biology (2010). Moreover, he was introduced as a Prominent Professor in the 3rd term of Allameh Tabatabaei's Award hosted by Iran vice Presidency for Science and Technology, Presidency and National Elite Foundation (2014). He is the winner of the United Nations Educational, Scientific and Cultural Organization (UNESCO)-Equatorial Guinea international prize (2014) for research in life sciences aimed at improving the quality of human life with his stem cell research and its numerous applications in regenerative medicine. 